\title{
A guasqueria e a sua função econômica ${ }^{1}$
}

\author{
Guasqueria y su funcion economica
}

\author{
Guasqueria and its economic function
}

\author{
Juliana Porto Machado ${ }^{2}$ \\ Ronaldo Bernardino Colvero ${ }^{3}$
}

\begin{abstract}
Resumo
A guasqueria é um saber fazer artesanal que se mantém por meio da transmissão oral das técnicas de trabalho com o couro cru. Através da desta matéria prima é possível a criação de diferentes objetos ligados a lida do campo. Mediante ao exposto, este artigo busca uma breve reflexão entorno da inserção dessa manifestação artesanal no mercado informal, a metodologia utilizada foi revisão bibliográfica.
\end{abstract}

Palavras-Chave: Guasqueria; Artesanato; Mercado; Globalização; Rural-urbano.

\section{Resumen}

Guasqueria es un conocimiento artesanal que se mantiene a través de la transmisión oral de técnicas de trabajo con cuero crudo. Mediante el uso de esta materia prima es posible crear diferentes objetos conectados al campo. Con base en lo anterior, este artículo busca una breve reflexión sobre la inserción de esta manifestación artesanal en el mercado informal, la metodología utilizada fue una revisión bibliográfica.

Palabras clave: Guasqueria; Manualidades; Mercado; Globalización; Rural-urbano.

\begin{abstract}
Guasqueria is an artisanal know-how that is maintained through the oral transmission of working techniques with rawhide. Through the use of this raw material it is possible to create different objects connected to the field. Based on the above, this article seeks a brief reflection on the insertion of this artisanal manifestation in the informal market, the methodology used was a bibliographic review.
\end{abstract}

Keywords: Guasqueria; Crafts; Market; Globalization; Rural-urban.

\section{Introdução}

A guasqueria ${ }^{4}$ se apresenta como uma prática realizada em espaço rural, principalmente por sujeitos que exercem a atividade de peão. Os produtos são criados através

\footnotetext{
${ }^{1}$ Este texto foi inicialmente apresentado no VI Jornada Brasileira de Sociologia, na UFPEL; com as sugestões apresentadas no evento o artigo possui algumas modificações. O mesmo está presente na edição especial da V edição do EHM, publicado nesta revista devido ao convite direcionado a organização do evento.

${ }^{2}$ Doutoranda em Memória Social e Patrimônio Cultural, UFPEL, bolsista FAPERGS, julianamachado209@gmail.com

${ }^{3}$ Doutor em História pela PUC-Porto Alegre, professor UNIPAMPA-São Borja, rbcolvero@gmail.com
} 
do couro cru, sendo o mais utilizado o bovino. A etimologia da palavra deriva de huasca pertencente ao dialeto quéchua e significa couro. Caracteriza-se por criar objetos voltados para a atividade campeira, principalmente as ligadas ao uso do cavalo.

Esse ofício segue uma estrutura dorsal ${ }^{5}$ que se apresenta com: a obtenção da matériaprima (o couro-cru animal, principalmente de bovinos) inicialmente através da chamada carneada, o estaquear o couro para secar ao sol, o lonquear de retirar os pelos da pele, o cortar as guascas (tiras de couro), o sovar as guascas para amaciar, e por fim tirar os tentos (as tiras de couro de diferentes espessuras) para assim produzir as tranças.

Sua origem está ligada com a introdução do gado vacum e dos equinos trazidos pelos europeus no século XVI no período das invasões. As terras mais ao sul do país, apresentavam clima e pastagens propícias para a alimentação e desenvolvimento desses animais, que formaram grandes rebanhos indômitos na região do pampa. Os animais eram a ser utilizado como fonte de subsistência por parte dos grupos étnicos que habitavam a região, de acordo com Luvizotto (2010) com a firmação das reduções jesuíticas, os bovinos passam a ser capturados e de certa forma domesticados, para serem utilizados como alimento e comercializados.

Destaca que no período das expulsões dos jesuítas em 1641, os padres deixam seus rebanhos e esses novamente se reproduzem livremente formando as chamadas Vacarias. Com a formação das estâncias os rebanhos passam pelo processo de domesticação e são confinados em sua maioria por cercas naturais, como áreas alagadas, pedras e outros materiais, já que até então não existia o arame.

Em um recorte temporal, no século XIX, com a alta exploração da carne e a queda na comercialização do couro, temos uma grande produção de couro, com a necessidade já existente da criação de objetos que pudessem auxiliar nas atividades do campo. Com isso, surgem os aparatos de montaria criados a partir do couro cru, como: as cabeçadas, laços, boleadeiras, rebenques e outros.

O peão que trabalha cotidianamente junto aos animais, passa a criar guasqueria, sendo contratado nesse período como guasqueiro pelas grandes estâncias de gado. Garcia (2009) irá mencionar que essa atividade não possui muito registro por estar ligada ao trabalho com

\footnotetext{
${ }^{4}$ Este artigo é um recorte da pesquisa de doutorado que se encontra em andamento no Programa de Pósgraduação em Memória Social e Patrimônio Cultural, cuja a temática é a produção de guasqueria em região de fronteira.

${ }^{5}$ A estrutura dorsal da guasqueria foi trabalhada na dissertação "Artesanato em couro cru (guasqueria) em Jaguarão-RS”, pesquisa que ainda se encontra em andamento.
} 
animais, o que era considerado sujo e primitivo, prejudicando imensamente a rememoração das memórias desse ofício secular, que carrega em si a identidade e a tradição dos guasqueiros.

A guasqueria pode ser compreendida como um ofício artesanal e como um produto artesanal que envolve o saber fazer. Ao considerarmos a guasqueria um ofício artesanal, esta irá sofre com o processo de reinterpretação em meio as transformações culturais da sociedade atual, quando utilizamos o artesanato para definir a guasqueria, consideramos que essa é um saber e um fazer que é transmitido entre pai e filho e entre peões, que iram construir suas obras não mais para auxiliar em sua atividade de lida, mas como um objeto a ser comercializado e que garanta sua sustentação financeira no novo espaço que passa a ocupar, a zona urbana.

Uma vez que, a guasqueria na cidade ${ }^{6}$, de Jaguarão- $\mathrm{RS}^{7}$, se desenvolve em espaço urbano, pois, o peão quando deixa de residir no campo e na guasqueria, encontra uma forma de estar em constante reafirmação de suas identidades e tradição, com a possibilidade de se manter economicamente. Para isso, ele adapta a criação dos objetos para atender a demanda do contexto mercadológico ao qual está inserido.

Reconhecendo sempre que o artesanato apresenta criações únicas, que possuem valor simbólico e memórias que possibilitam múltiplas interpretações socioculturais, a guasqueria pode ser considerada como um artesanato tradicional. Corroborando com essa ideia, o Programa de Artesanato Brasileiro (2012; p.22) afirma que envolve um "conjunto de artefatos mais expressivos da cultura de um determinado grupo, representativo de suas tradições e incorporados à vida cotidiana, sendo parte integrante e indissociável dos seus usos e costumes". Logo, a guasqueria se insere no rol de produtos que representam e identificam um grupo social.

Por conseguinte, este artigo tem por objetivo refletir entorno da importância do mercado informal artesanal principalmente com foco no ofício de guasqueria na cidade de Jaguarão-RS; por meio de entrevistas semiestruturadas com quatro guasqueiros.

\section{A produção artesanal e o mercado informal}

A pratica artesanal ao ser conceituada perpassa pelas dimensões socias, culturais, políticas, temporais e humanas. Este ofício detém em si capital humano e valor simbólico.

\footnotetext{
${ }^{6} \mathrm{O}$ termo cidade e espaço urbano, assim como rural e campo serão neste artigo utilizados como sinônimos.

${ }^{7}$ Jaguarão é uma cidade que se localiza na região sul do Rio Grande do Sul, fazendo fronteira com a cidade de Rio Branco no Uruguai.
} 
Pode ser compreendido como heterogêneo, uma manifestação cultural que se mantém entre modernidade e tradição. Sua valorização pode ser percebida pelas características que apresenta, como a inclusão social dos sujeitos que o praticam, já que é fonte de sustentação econômica, uma profissão e um condutor de rememorações das identidades e das memórias locais.

Memórias locais que podem ser interpretadas por meio da memória coletiva. de acordo com Halbwachs (1990), essa tem como base de sustentação as lembranças do outro, uma vez que a confiança estabelecesse quando ocorre um compartilhamento e uma troca de apoio entre lembranças, principalmente quando ocorre a necessidade de evocar a memória de um grupo. Pois, mesmo que o evento tenha ocorrido com apenas a presença do $e u$, com ações que apenas $e u$ presenciei, mesmo nesta situação nunca estamos isolados do contexto social e só identificamos o acontecimento por meio das referências criadas com o outro em sociedade.

Então, as lembranças individuais rememoradas por um sujeito, não pertencem apenas a ele, porque, até mesmo ao se identificar como ser humano ele estará utilizando memórias simbólicas calcadas em referencias sociais, que foram estabelecidas em conjunto entre o $\mathrm{eu}, \mathrm{o}$ outro e o nós. As memórias que cada sujeito carrega em si foram criadas e vivenciadas coletivamente e afetam diretamente suas ações e escolhas.

Em meio a memórias construídas coletivamente, o artesanato, pode ser definido como a transformação da matéria-prima em seu estado natural em objetos carregados de imaginação, técnica e possibilidade de comercialização. É uma produção essencialmente manual, realizado muitas vezes por apenas um artesão, que é especialista nas técnicas de criação, podendo ou não utilizar alguma ferramenta industrial, porém sua participação não é central, a mesma só é utilizada como apoio.

Para Keller (2014) a base de criação do artesanato se concentra no trabalho manual, produzido em sua grande maioria por grupos familiares que buscam complementar sua renda e que pertencem a sociedade contemporânea. Dessa forma, um objeto artesanal irá seguir um processo de criação, circulação e manutenção, tornando-se também, um produto econômico, que poder ser comercializado e consumido, desde que se adapte as demandas do mercado. No entanto, uma peça artesanal por ser comercializada não irá perder seu valor simbólico e humano, ela apenas será integrada ao sistema de vendas, que em sua maioria se caracteriza pelo mercado informal.

Martins (1973) irá apresentar a existência-e algumas características que são essenciais para a estruturação do artesanato, como o predomínio do manual com ferramentas criadas pelo próprio artesão, afastando-se completamente dos objetos mecanizados. Em sua origem 
manual cada peça será única, demonstrando a técnica e a habilidade do artesão, que irá utilizar as mãos em sincronia com a mente. Por serem únicos os objetos não adentraram a um padrão de seriado. De alguma forma, as obras possuem uma função, mesmo quando estejam confeccionados em meio as habilidades artísticas do artesão. Assim, a matéria-prima utilizada será da natureza, com pouco ou nenhum valor econômico.

$\mathrm{Na}$ situação da guasqueria, em Jaguarão, devido as transformações na área rural principalmente com a mecanização e o avanço das lavouras de soja, as estâncias de gado estão diminuindo progressivamente, fazendo com que não tenha tanto peão atuando no campo. Isso ocasiona o desparecimento das chamadas carneadas em dias de marcação, nas carneadas e em tempo de abate os guasqueiros conseguiam o couro de forma gratuita, atualmente os mesmos compram a um preço alto, porém a matéria-prima ainda segue sendo natural.

Sanches e Santos (2010) consideram o artesão como o indivíduo que tem habilidades e domina a técnica manual, para transformar a matéria-prima em objetos de diferentes formas e matérias. Desse modo, o cerne do artesanato é a força motriz da criação ser manual, provir do artesão, possuidor de liberdade para organizar a produção de acordo com seu tempo, a escolher a matéria-prima a ser transformada e as técnicas a serem aplicadas.

Dessarte, o artesanato apresenta uma forte relação com a tradição, devido a ser um ofício de criação cujo o aprendizado ocorre por meio da transmissão do saber fazer de uma geração a outra, permanecendo com poucas mudanças. Alvim (1983) alerta que pensar o ofício artesanal como sinônimo de tradição, faz com que o mesmo esteja em oposição a modernidade, afetando sua atuação em sociedade.

Por muito tempo a tradição teve o caráter da estagnação, do imutável, em que se conserva sempre pura, isso foi uma resposta a modernidade, pois era conceituada como os costumes e ritos do passado que eram transmitidos sem quaisquer modificações. Pontua Hobsbawm e Ranger (1984) considerar a tradição como imutável, que transmite apenas elementos do passado sem alterações, a torna sem sentido e valor cultural. Visto que, a tradição é o vínculo entre o passado e o presente, se ajusta as necessidades do sujeito social e por isso são mutáveis, permanece alguns resquícios e outros são reinterpretadas. Com isso, a tradição é uma invenção, construída no passado sendo ou não capaz de prosseguir no futuro.

A tradição tal qual o artesanato é uma invenção humana, uma forma encontrada para responder uma necessidade, sendo transmitida e retransmitida em meio a diversas interpretações. Com afirma Lenclud (2013) improvável de se conservar em seu estado original em uma sociedade que está sempre em movimento. Sendo preciso que ocorra as concessões entre criar, conservar e transformar, para que os saberes tradicionais sobrevivam 
ao ciclo natural de mudanças do tempo e do espaço. Do contrário, irão desaparecer, e novos hábitos e costumes serão desenvolvidos.

Na mesma direção, Candau (2009) argumenta que uma tradição se conserva quando existe uma memória forte, em que se estabeleçam elementos comuns aos sujeitos que compõem um grupo, pois esses sujeitos iram transmitir e interpretar continuamente a tradição até o momento que ela desapareça ou que não seja mais necessária.

Do mesmo modo que a tradição, o artesanato irá se adaptar ao contexto que está inserido, para se manter atuante. Conseguindo, conservar o trabalho manual sem a utilização massiva de máquinas industriais, com valor e bases locais, com um ritmo próprio de produção e com um sistema de comercialização informal. É de certa maneira oposto do processo industrial calcado em quantidade em menor escala de tempo, divisão de trabalho e especialização das atividades, no qual um único sujeito não domina ou conhece todas as etapas de criação de um objeto. Nessa direção, o guasqueiro J.S (2018) irá mencionar que “isso aqui não é uma fábrica, não vai sair tudo perfeito, isso é artesanato [...] eu crio no meu tempo, se estou mau, sem vontade eu fecho a porta e paro de trabalhar e deixo para o outro dia".

Para Canclini (1983) os objetos artesanais populares auxiliam na renovação do mercado consumidor, com a introdução de produtos com técnica, desenhos originais e custo baixo afastando-se do modelo de produtos padrões. O guasqueiro J.S (2018) menciona que o a guasqueria oferece objetos únicos, que apesar de serem próximos esteticamente, ainda sim serão diferentes do industrial que tudo sai perfeito e igual. Como no caso das tranças "eu crio o desenho, conto as passadas necessárias que eu preciso, porque cada trança vai ser diferente da outra [...] se eu errar a passada de um tento, tenho que iniciar todo o trabalho de novo (Figura 01).

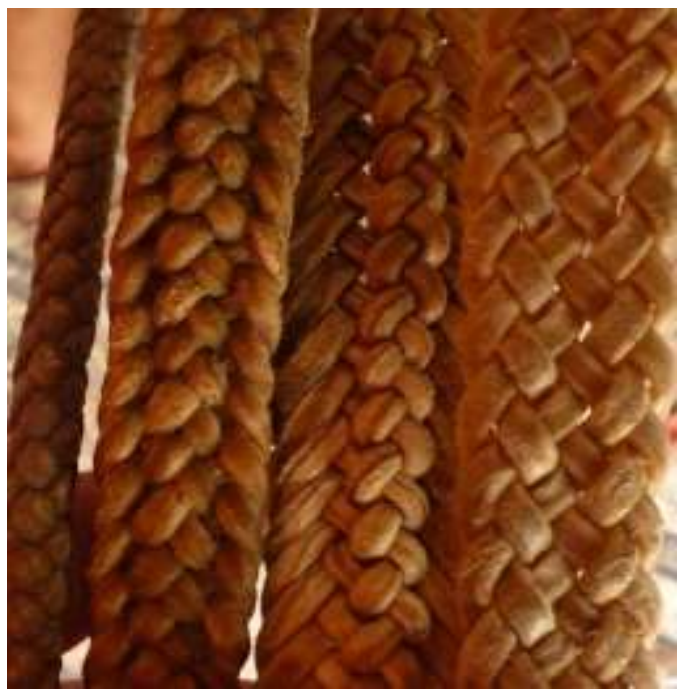

Figura 1-Tranças de couro cru Fonte: 
Em relação a produção industrial Barroso (2000) considera que essa causou no artesanato a marginalização cultural, social e econômica. Em razão disso, o artesanato atua frente as comunidades periféricas que não possuíam acesso e nem formas de adquirirem produtos e serviços oferecidos pela industrialização. Com efeito, a produção artesanal com base no seu formato de execução não poderia competir de forma igualitária com os objetos industriais de larga escala. Todavia, o artesanato deve ser considerado pela sua importância cultural e pela sua inserção no mercado informal, sendo meio de sustentação de muitos grupos sociais.

Sem embargo, o artesanato proporciona oportunidades de emprego e consequentemente é mecanismo de desenvolvimento econômico. Desenvolve-se no seio familiar e em espaços próprios, caracterizando-se por ser um ofício de base informal. Em relação a guasqueria, os guasqueiros constroem seus ateliês no espaço residencial, guiando-se em um estilo próximo a organização existente em um galpão, os objetos são criados e dispostos em mostruários, como se estivesse pronto para serem utilizados na lida campeira, remetendo sempre a memória de que foram e ainda são peões e guasqueiros.

As autoras Alves e Almeida (2009) argumentam que a informalidade ocorre também, pelo desinteresse que muitos artesãos tem em se associarem a projetos governamentais e perderem outros auxílios que possuem, como a aposentadoria. O guasqueiro M. T (2018) salienta que não se considerava artesão, que essa categoria passou a ser utilizada quando foi se registrar como profissional autônomo praticante do ofício de guasqueria. Porém, esse ofício acabou por ser considerado pela entidade pública como artesanato, causando certa dificuldade de identidade para o guasqueiro M.T (2018) que se considerava só guasqueiro e desconhecia a relação com o artesanato.

De certa forma, neste caso específico houve o interesse por parte do guasqueiro em formalizar em seu ofício. Ele comercializa suas peças no armazém de alimentos que possui, suas vendas de maior quantidade ocorrem por encomendas, principalmente em época de festas tradicionais, como a semana farroupilha.

Em outra situação, tem-se o guasqueiro J. S (2018) que produz guasqueria como profissão, sua principal e única fonte de sustentação. O mesmo acrescenta que cria o que o mercado pede, suas peças são comercializadas para agropecuárias espalhadas pela cidade e também por meio de encomendas para outros estados.

Eu faço para me manter e manter minha família, eu abandonei os estudos, fui para o campo e me tornei peão lá eu vi alguém guasquear, me apaixonei, daí comecei a observar e treinar em casa, usei muito manual e livros pesquisei principalmente em 
livros chilenos e argentinos [...]busquei me especializar, abri um negócio e fali, voltei dois anos depois e tentei de novo e fali, daí agora fazem três anos que estou aqui e dominei o mercado de Jaguarão, meu produto está em todas as veterinárias e agropecuárias.[...] pesquisei muito, fui atrás dos guasqueiros mais antigos e observei, recorri a cidade inteira e fui só nos melhores [...] não há uma concorrência entre guasqueiros para espaço de venda, porque a maioria já é aposentado e fazem porque gostam, mas eu preciso me manter [...] isso é um mercado (J.S, 2018).

A situação apontada pelo guasqueiro J.S demonstra que os guasqueiros da cidade que se encontram em uma faixa etária avançada deixaram de exercer a atividade de peão porque, se aposentaram e começaram a guasqueria como uma forma de estarem em contato com suas memórias e também, como uma complementação de renda. Já os guasqueiros com uma faixa etária mais nova apresentam-se na guasqueria como profissão, como fonte principal de renda e buscam aperfeiçoamento de técnicas e novos designs para os produtos, não demonstram receio de utilizarem máquinas industriais para facilitar a produção. Mas, nas duas situações a comercialização das peças ocorre por meio do mercado informal.

O trabalho formal caracteriza-se pela regulação das atividades, garante certa segurança como o direito a Previdência Social, seguro desemprego, férias e fundo de garantia. Por outro lado, a atividade informal acontece com pouca interferência do governo, possibilitando escolher a forma que se deseja trabalhar. O guasqueiro M.T (2018) relata que seu horário de trabalho é flexível, mas sempre busca trabalhar até terminar as peças que iniciou e as encomendas.

Correa e Lopes (2009) apontam que as recessões que assolaram o Brasil nos anos 90, juntamente com o estabelecimento de políticas anti-inflacionárias, ocasionaram um pequeno crescimento econômico, mas não o suficiente para aplacarem as crises financeiras que o país sofreu concomitante com a queda de contratação de mão de obra nas industrias, contribuíram assim para o aumento do desemprego e do trabalho informal.

O guasqueiro M.C (2018) aponta que as estâncias se modificaram em meio ao crescimento das lavouras de soja e arroz. A partir dos anos 90, o gado acaba por ser reduzido em sua visão, pois, antes quando era mais jovem as estâncias tinham muitos peões, atualmente, como no caso da estância em que trabalha tem apenas ele e o outro para cuidar da lida.

No sentido do crescimento desmedido das lavouras o guasqueiro M.T (2016) já declarava o seu temor aos agrotóxicos que terminam com o gado e as pastagens, neste destacava que quem foi campeiro foi, e quem não foi não será mais. O guasqueiro P.P (2017) também, se posicionou neste assunto ao dizer que antes conseguia o seu couro pela carneada, havia muito gado, as estâncias em época de marcação eram uma festa, porém, isso terminou. 
Está cada vez mais difícil conseguir um couro-cru presenteado; só acontece quando algum conhecido traz para ele.

Como expõe Queiroz (1973), no espaço rural, com a modernidade as crises econômicas acarretaram a queda na produção pastoril e consequentemente na remuneração das famílias que vivem da exploração agropecuária de pequeno porte, assim como na contratação de mão-de-obra, atualmente um peão realiza o trabalho de dez. Quando se trata do espaço rural, comumente esse contexto, se reconstrói em meio a atores sociais que o ocupam, como as figuras do pequeno agricultor familiar que cultiva pequenas áreas e possui alguns animais, e dessa terra tira o sustento econômico. Entretanto, o peão que trabalha no campo mediante um salário, serve aos interesses de um patrão ${ }^{8}$.

O autor ressalta a mudança na forma de desenvolvimento econômico das estâncias que contemporaneamente utilizam parte de suas terras para a soja e o arroz, como no caso de Jaguarão, e para o gado de corte. Após a colheita, em tempo de resteva ${ }^{9}$ adquirem-se mais animais, para assim, em um sistema de rotação esses se alimentam da pastagem, entram no processo de engorda para serem comercializados, muitas vezes a criação do gado acaba sendo uma atividade secundária. Essa situação faz com que não haja a necessidade de contratar um grande número de peões para a lida com os animais.

Para Brandenbug (1998) os espaços sem ocupação no meio rural se dão pela forma de implementação das grandes estâncias, que se organizavam na tomada da área com diversas construções como os galpões, currais, casas de hóspedes, casas dos colonos, e principalmente pela ausência constante do estancieiro. Assim, na urbanização e modernização essa figura passa a ser alegórica, utiliza a estância para os finais de semana, deixa para os empregados o cuidado com a lida campeira.

\section{Considerações finais}

A guasqueria está intrinsecamente ligada aos sujeitos que ocupam o espaço rural e exercem as atividades do campo, principalmente a de peão, que estabelece uma relação de troca entre sujeito, natureza e animais. $O$ peão passa grande parte de sua vida trabalhando em estâncias como contratado, sendo a base da hierarquia presente nesse contexto, da tríade patrão, capataz e peão.

É um ofício que trabalha com couro cru e ferramentas manuais, permeia as dimensões tradicionais através da transmissão do saber fazer de uma geração a outra, por meio da

\footnotetext{
${ }^{8} \mathrm{O}$ dono das terras, o estancieiro.

${ }^{9}$ A base dos cereais que fica presa aos terrenos de cultura depois da colheita, e que são ricas em nutrientes.
} 
repetição de técnicas de produção. A produção ocorre em ateliês que se aproximam da imagem dos galpões de estâncias. Nesses lugares encontram-se as obras em fase de inicial e as finalizadas, no meio de um contexto que é familiar ao guasqueiro que rememora ao passado de trabalho no campo.

Os ateliês são lugares aparte da casa, isso porque estão carregados de inspirações, sentidos e lembranças dos tempos vividos pelos guasqueiros/peões e também, como um elemento rural remanescente na região urbana. São também, lugares de memórias criados pelos sujeitos diante da contemporaneidade frente as crises manifestadas dos paradigmas modernos, nesses lugares os sujeitos irão encontrar a sua essência, refletir, identificando-se como intermediador de seu tempo e construindo novas imagens do passado (NORA, 1993).

Então, a guasqueria está vinculada a uma prática específica, o trabalho de peão de estância de gado, seguindo uma tradição de compartilhamento e aprendizado de um saber, transmitido de pai para filho e de guasqueiro para guasqueiro. E sua comercialização ocorre por meio do mercado informal, que oferece caminhos para a sustentação dos guasqueiros/peões.

Embora a produção de guasqueria seja realizada em contexto urbano, em Jaguarão, a mesma ainda permanece as margens, sendo pouco ou nunca reconhecida, envolta pelo esquecimento, é desconhecido para aqueles que não possuem ligação com o cavalo ou campo. Por fim, o peão sustenta suas memórias em uma constante reafirmação em espaço urbano, principalmente através da prática de guasqueria, mediante a transformações da organização das estâncias, como a queda na exploração na área da pecuária e o aumento da produção de soja e arroz. O peão acaba por não ter espaço para atuar e volta-se para o meio urbano e o mercado informal como alternativa de sobrevivência, encontra na guasqueria uma forma de obter recursos monetários e de rememorar sua identidade de homem do campo.

\section{Referências}

ALVIM, Maria Rosilene Barbosa. Artesanato, tradição e mudança social - Um estudo a partir da "arte do ouro" de Juazeiros do Norte. In: RIBEIRO, Berta et al. O artesão tradicional e seu papel na sociedade contemporânea. Rio de Janeiro: FUNARTE/Instituto Nacional do Folclore, 1983.

ALVES, Ana Elizabeth Santos; ALMEIDA, José Rubens Mascarenhas de. Trabalho informal em tempos "globalizacionistas". Revista Histedbr On-line, Campinas, n'. Especial, Maio,2009.

BARROSO, Eduardo Neto. O que é artesanato. Módulo 1. 2000. Disponível em: http://rededegestoresecosol.org.br Acesso em 20 de agosto de 2019. 
BRANDENBURG, Alfio. Colonos: subserviência e autonomia. In: FERREIRA, Â.; DAMASCENO, D.; BRANDENBURG, A. Para pensar outra agricultura. Curitiba: Ed. UFPR, 1998.

CANCLINI, Néstor Garcia. Culturas Híbridas: estratégias para entrar e sair da modernidade. Trad. Ana Regina Lessa e Heloísa P. Cintrão. São Paulo: Edusp, 2008.

CANDAU, Joel. Memória e Identidade. São Paulo: Contexto, 2009.

CORREA, Rosilda; LOPES, Janete Leige. Mercado de Trabalho Informal: Um comparativo entre Brasil e Paraná numa trajetória de "10 anos". IV Encontro de produção Científica e Tecnológica, $2009 . \quad$ Disponível em: http://www.fecilcam.br/nupem/anais_iv_epct/PDF/ciencias_sociais/11_CORREA_LOPES

Acesso em 21 de agosto de 2019.

GARCÍA, Rocío. De la yerra a la Vitrina: Transformaciones contemporáneas de la guasquería. Montevideo: Trama Revista de Cultura y Patrimonio. ano 1, nº 1, setembro 2009.

HALBWACHS, Maurice. Memória Coletiva. RJ:Vertice, 1990.

HOBSBAWM, Eric \& RANGER, Terence. A Invenção das Tradições. Rio de Janeiro:Paz e Terra, 1984.

KELLER, Paulo. $O$ artesão e a economia do artesanato na Sociedade contemporânea. Maranhão: Revista de Ciências Sociais Política e Trabalho, 2014.

LENCLUD, Gérard. A Tradição não é mais o que era: sobre as noções de Tradição e de Sociedade Tradicional em Etnologia. Brasília: História, histórias. vol. 1, n. 1, 2013.

LUVIZOTTO, Caroline Kraus. As tradições gaúchas e sua racionalização na modernidade tardia. São Paulo: Editora UNESP; São Paulo: Cultura Acadêmica, 2010.

MARINHO, Heliana. Artesanato: tendências do segmento e oportunidades de negócios, 2009.

MARTINS, Saul. Contribuição ao estudo científico do Artesanato. Belo Horizonte: Imprensa oficial do Estado de Minas Gerais, 1973.

NORA, Pierre. Entre memória e história: a problemática dos lugares. Projeto História. São Paulo: PUC-SP. N 10, p. 12. 1993.

SANCHES, Lucinéia; SANTOS, Marina Alcântara dos. A. A assessoria técnica para a produção de artesanato na economia solidária desenvolvida pelo profissional de moda como possibilidade de inclusão social: o caso Enloucrescer. Natal, 2010. Disponível em: http://www.cchla.ufrn.br/cnpp/pgs/anais/ Acesso em: 28 de agosto de 2019.

QUEIROZ, Maria Isaura Pereira de. O campesinato brasileiro: ensaios sobre civilização e grupos rústicos no Brasil. Petrópolis: Vozes, 1973. 